\title{
Mengubah Panas Buang Heater Mesin Injeksi Menjadi Energi Listrik dengan Peralatan Berbasis Termoelektrik
}

\author{
Agus Kurniawan*, Alexander Satya Wiratama, Faris Abyan Adam, Hendsan \\ Bhinar Prayoga, Taji Harya Prakosa \\ Program Studi Perancangan Manufaktur, Politeknik ATMI Surakarta, \\ Jl. Mojo no 1, Karangasem , Laweyan, Surakarta 57145 \\ *Penulis korespondensi: agus.kurniawan@atmi.ac.id
}

Histori artikel: diserahkan 05 September 2020, direviu 10 September 2020, direvisi 16 September 2020

\section{ABSTRACT}

\begin{abstract}
This final project makes a device that produces electrical energy by utilizing waste heat from injection machines. The waste heat of the injection machine is converted into electrical energy using a thermoelectric. This device consists of an aluminum heatsink, aluminum plate, thermoelectric, MDF wood planks, engine gasket, and thermal paste. The hot side heat sink receives the heat generated by the injection machine, four thermoelectric units, and the cold side heat sink. Thermoelectrics was arranged in a series method. The thermoelectric output is connected to a multimeter to test the amount of voltage and current generate. The number of thermoelectricbased equipment was made of two pieces and assembled in series. The test was carried out using an open-circuit and a closed-circuit with a load using a 1-watt LED lamp $(\Omega 55 \Omega)$. The open-circuit test results show that the largest voltage is generated at 10.80 volts with a hot side temperature of $108^{\circ} \mathrm{C}$ and a cold side temperature of $64^{\circ} \mathrm{C}$. The closed-circuit test results show that the most significant voltage produced is 2.64 volts with a hot side temperature of $108^{\circ} \mathrm{C}$, and a cold side temperature of $62^{\circ} \mathrm{C}$. When thermoelectric based equipment is given a load, the voltage decreases because it is divided into the given load. This equipment can be applied to turn on as many as five lamps with 1 watt's power, supporting production activities in the injection workshop.
\end{abstract}

Kata kunci: Thermoelectric, alternative energy, heat loss

DOI: https://doi.org/10.18196/jqt.020116

Web: https://journal.umy.ac.id/index.php/qt/article/view/9536

\section{PENDAHULUAN}

Mesin injeksi (plastic injection) atau mesin molding adalah mesin yang memiliki fungsi untuk mencetak berbagai bentuk benda dengan menggunakan material mentah berupa biji plastik. Di dalam unit injeksi terdapat suatu komponen yang dinamakan Cylinder Barrel. Cylinder Barrell ini berbentuk tabung panjang atau silinder yang disusun horizontal terhadap mesin injeksi. Cylinder Barrel berfungsi sebagai tempat pencairan biji plastik menjadi cairan leleh plastik yang nantinya akan disuntikkan ke cetakan benda diminta. Silinder ini dibungkus dengan elemen panas (heater) yang berfungsi sebagai pemanas material yang berada didalam barrel. Material industri yang sering dikerjakan pada bengkel WI, seperti material PVC (Polyvinyl Chloride) memiliki titik lebur (100-125) ${ }^{\circ} \mathrm{C}$, PE (Polyethylene) memiliki titik lebur (115-171) ${ }^{\circ} \mathrm{C}, \quad \mathrm{PP}$ (Polypropylene) memiliki titik lebur (130-170) ${ }^{\circ} \mathrm{C}$. Temperatur pemanas dapat kita atur sesuai dengan melting point material yang akan kita pergunakan. Rata - rata suhu barel yang digunakan pada mesin injeksi bengkel WI adalah $150{ }^{\circ} \mathrm{C}$. Pada saat heater memanaskan material sudah dapat dipastikan bahwa panas yang dibuat oleh heater tidak tersalurkan sempurna, pasti akan terdapat sisa kalor yang terbuang, kalor yang terbuang tersebut dinamakan waste heat. Dalam dunia industri, panas yang terbuang tersebut memang belum banyak dimanfaatkan. Perbedaan panas tersebut dapat menimbulkan gelombang akustik yang dapat dirubah menjadi energi listrik (Anugrah R.A., 2019). Termoelektrik memiliki perbedaan pada alat yang digunakan untuk merubah panas menjadi energi listrik yaitu berdasarkan efek Seebeck (apabila dua buah logam diberikan 
suhu yang berbeda pada ujungnya maka timbul tegangan ujung satu dangan ujung yang lain).

Termoelektrik adalah suatu alat teknologi yang dapat mengkonversi energi panas menjadi energi listrik secara langsung, atau sebaliknya, yakni dari energi listrik menjadi energi panas. Dalam penggunaan termoelektrik, bahan yang dipakai umumnya bersifat semi konduktor. Semi konduktor merupakan bahan yang dapat menghantarkan arus listrik namun tidak sempurna. Ryanuargo et.al. (2013), Aplikasi termoelektrik yang dapat sering kita jumpai dalam kehidupan sehari hari adalah pada dispenser air. Dapat kita tahu dispenser dapat menjadikan air panas atau dingin, ini merupakan kemampuan termoelektrik yang dapat mengubah energi listrik menjadi energi kalor. Berbeda dengan pemanfaatan termoelektrik pada kompor yang dimanfaatkan untuk menyalakan lampu penerangan. Termoelektrik ini bertindak sebagai generator dengan memanfaatkan panas buang dari kompor untuk diubah menjadi energi listrik.

Penelitian ini akan membuat alat untuk memanfaatkan waste heat mesin injeksi berbasis termoelektrik. Waste heat mesin yang digunakan berasal dari heater yang terdapat pada bagian barel mesin injeksi. Barel berfungsi untuk mencairkan biji-biji plastik sebelum di injeksikan kedalam mold. Termoelektrik yang digunakan adalah termoelektrik generator (TEG), yang mempunyai efek peltier, yaitu dapat mengubah energi kalor menjadi energi listrik. Termoelektrik generator akan dipasang pada suatu alat yang didesain agar dapat memaksimalkan energi kalor, kemudian alat tersebut akan diletakkan dibagian luar barel mesin injeksi. Tegangan dan arus yang keluar dari alat tersebut akan diuji dengan menggunakan alat ukur multimeter. Hasil keluarannya berupa tegangan dan arus akan dianalisa. Semakin besar perbedaan temperatur antara bagian yang menempel pada heater dengan tempratur udara di sekitar termoelektrik, maka semakin besar juga tegangan dan arus listrik yang dihasilkan.

\section{TINJAUAN PUSTAKA}

\section{Cylinder Barrel}

Salah satu komponen terpenting pada mesin injeksi adalah Cylinder Barrel. Cylinder Barrel adalah silinder atau tabung yang berfungi sebagai tempat material plastik yang sudah cair. Cylinder barrel juga berfungsi sebagai jalur plastik cair menuju ke cetakan. Silinder ini dibungkus dengan elemen panas (heater) yang berfungsi sebagai pemanas material yang berada didalam barel. Banyaknya heater juga mengikuti besarnya barel mesin injeksi. Ukuran diameter barel bervariasi mulai dari $50 \mathrm{~mm}$ hingga $500 \mathrm{~mm}$. Panas yang dihasilkan dari barel sendiri rata rata berada diangka $100^{\circ} \mathrm{C}$ $250^{\circ} \mathrm{C}$ tergantung dari titik leleh biji plastik yang akan dicairkan

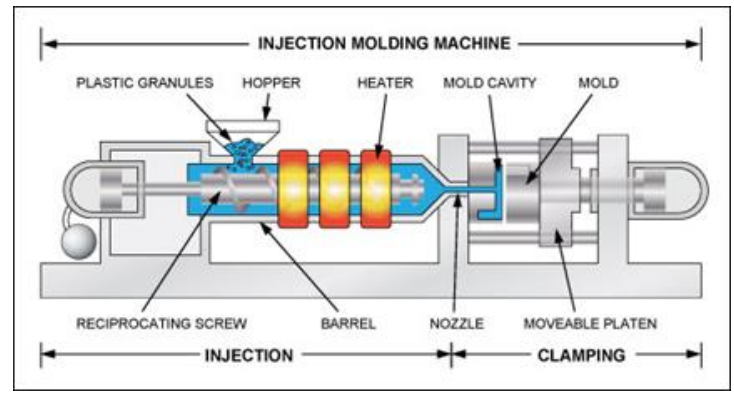

GAMBAR 1. Bagian-bagian mesin injeksi

\section{Thermoelectric}

Termoelektrik adalah suatu alat untuk mengubah energi panas menjadi energi listrik dan sebaliknya jika tegangan dialirkan pada termoelektrik maka akan menciptakan perbedaan temperatur pada kedua sisi nya. Termoelektrik dipengaruhi oleh beberapa efek yaitu efek seebeck dan peltier. Membutuhkan sumber panas dan sumber dingin untuk dapat menghasilkan perbedaan suhu yang nantinya akan diubah menjadi tegangan oleh termoelektrik yang dapat dimanfaatkan. Struktur TEG terdiri dari suatu susunan tipe-n (material kelebihan elektron) dan tipe-p (material kekurangan elektron). Salah satu sisi dipanaskan sehingga temperature lebih tinggi dari sisi yang lain. Elektron pada ujung sisi logam yang dipanaskan memiliki energi kalor yang lebih besar dibandingkan elektron dengan ujung yang lebih dingin. Pada tahap ini kenetralan atom terjaga, sehingga distribusi 
elektron membentuk muatan negatif pada ujung dingin (kelebihan elektron) dan muatan positif. Pada kasus ini, akan digunakan termoelektrik dengan jenis Termoelektrik Generator (TEG) seperti penelitian yang telah dilakukan oleh Khalid et al. (2013) dan Andrapica et al. (2015). Termoelektrik ini merupakan jenis termoelektrik yang akan menghasilkan listrik jika mendapatkan perbedaan temperatur/ suhu pada masing-masing sisi (sisi panas dan sisi dingin). Untuk memanfaatan atau mengubah dari delta suhu menjadi listrik, diperlukan TEG.

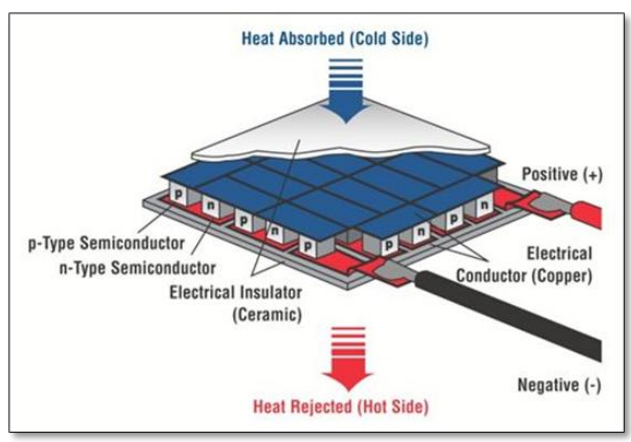

GAMBAR 2. Prinsip kerja thermoelectric

\section{Perhitungan}

\section{Arus, Tegangan, Hambatan dan Daya}

Rumus-rumus dasar tegangan dan arus juga digunakan untuk memilih rangkaian terbaik yang digunakan termoelektrik untuk menghasilkan tegangan dan arus yang dapat difungsikan sebagai sumber listrik lampu LED. Rumus perhitungan daya yang terjadi pun juga menggunakan rumus-rumus dasar yang akan saling terikat dengan tegangan, arus, dan hambatan yang terjadi (Andrapica et al., 2015). Rumus-rumus dasar tersebut:

$$
\begin{aligned}
& I=\frac{V}{R} \\
& V=I \times R \\
& R=\frac{V}{I} \\
& P=V X I
\end{aligned}
$$

dimana I adalah arus listrik yang mengalir (Ampere/A), $\mathrm{V}$ adalah tegangan listrik yang dihasilkan (Volt/V), $\mathrm{R}$ adalah hambatan yang ada pada rangkaian $(\mathrm{Ohm} / \Omega)$ dan $\mathrm{P}$ adalah daya listrik yang terjadi (Watt).

\section{Perpindahan Panas}

Sesuai prinsip kerja termoelektrik yang digunakan dalam alat yang akan dibuat, panas hasil buangan dari mesin injeksi dan udara sekitar adalah salah satu faktor penting yang mempengaruhi besarnya arus dan tegangan yang dihasilkan oleh prototipe ini. Maka metode perambatan panas dipilih dari keefektifan panas yang merambat menggunakan media berupa plat allumunium dan heatsink, demi menghasilkan perpindahan panas yang maksimal dan efektif serta tidak memerlukan waktu yang lama untuk merambat. Prinsipnya menggunakan 2 cara perpindahan panas yaitu konduksi dan konveksi.

Perpindahan panas konduksi adalah perpindahan panas yang menggunakan media perantara yang tidak ikut berpindah. Artinya, partiker-partikel media perambatan panas ini tidak ikut berpindah layaknya kalor yang berpindah. Perpindahan panas ini hanya terjadi di benda padat, dan hanya akan terjadi bila ada sentuhan atau hubungan antar benda bersuhu rendah dengan benda bersuhu tinggi atau bahkan sumber api. Perpindahan jenis ini dipengaruhi oleh faktor terkait sifat material tersebut dapat/ tidak dapat merambatkan panas. Sebatang besi jika dipanaskan akan lebih cepat panas dari ujung ke ujung daripada sebatang kayu yang dipanaskan. Hal itu disebabkan oleh faktor koefisian thermal yang dimiliki oleh besi tersebut lebih besar dibanding koefisian thermal yang dimiliki oleh kayu. Pada kasus perambatan panas konduksi, tidak semua material dapat merambatkan panas dengan metode ini. Hanya material yang memiliki koefisien thermal tinggi/material isolator yang dapat menerapkan perambatan panas konduksi. Perpindahan panas jenis konduksi ini adalah metode perpindahan panas utama yang akan digunakan dalam prototype untuk menyalurkan panas dari kalor hasil buang mesin injeksi ke termoelektrik. Berikut adalah persamaan dari perpindahan kalor secara konduksi (Burlian et al. (2014);

$$
Q=\frac{k \cdot A \cdot \Delta T}{\Delta x}
$$

dimana $\mathrm{Q}$ adalah laju perpindahan panas $(\mathrm{KJ} /$ $\mathrm{dt}$, watt), $\mathrm{K}$ adalah koefisien konduksi thermal (W/mK), A adalah luas penampang batang $\left(\mathrm{m}^{2}\right), \Delta \mathrm{x}$ adalah Panjang lintasan perpindahan kalor (m) dan $\Delta \mathrm{T}$ adalah perbedaan suhu $(\mathrm{K})$. 
Konveksi adalah perpindahan panas yang menggunakan media perantara yang ikut berpindah sebagai sarana perambatan panas atau kalornya. Perambatan panas jenis konveksi ini biasanya terjadi pada zat cair dan gas. Kalor berpindah melalui uap yang naik keatas. Uap dari air yang menguap ke atas adalah media dari kalor untuk merambat. Pada perpindahan panas konveksi ini, bisa disebutkan bahwa kalor dipaksa berpindah dari satu media ke media lain. Rumus laju perpindahan panas secara konveksi (Burlian et al., 2014) yaitu;

$H=\frac{Q}{t}=h . A . \Delta t$

dimana $\mathrm{H}$ adalah laju perpindahan panas $(\mathrm{J} / \mathrm{s}$, watt), Q adalah Kalor (J), t adalah Waktu (s), h adalah koefisien konveksi thermal $\left(\mathrm{j} / \mathrm{sm}^{2} \mathrm{~K}\right)$, A adalah luas penampang batang $\left(\mathrm{m}^{2}\right)$, dan $\Delta \mathrm{t}$ adalah perbedaan suhu (K).

\section{METODE PENELITIAN}

Penelitian ini dilakukaan di Politeknik ATMI Surakarta. Metedologi penelitiannya adalah sebagai berikut.

\section{Pembuatan Alat}

Proses pembuatan alat terdiri dari proses perancangan, proses pencarian bahan, proses pengerjaan, dan proses perakitan, Rancangan awal alat yang akan dibuat dapat dilihat pada gambar 3.

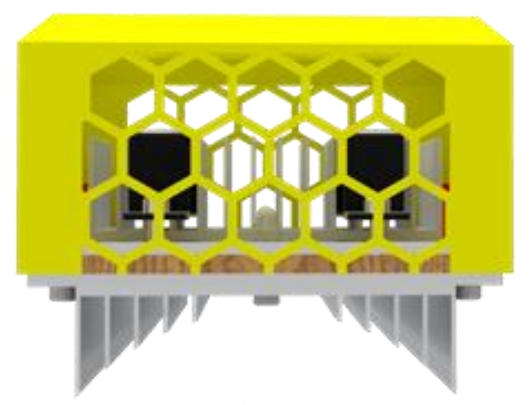

GAMBAR 3. Rancangan alat

\section{Pengujian Alat}

Pengujian akan dilakukan dengan sumber panas berupa panas buangan dari mesin injeksi dan sumber dingin dari udara sekitar dan fan/ kipas kecil. Proses pengujiannya dilakukan dalam dua rangkaian pengujian, yaitu rangkaian terbuka (Gambar 4) yang langsung terhubung dengan multimeter sebagai pengukur dan rangkaian tertutup (Gambar 5) yang diberi beban berupa lampu LED dengan hambatan sebesar $55 \mathrm{ohm}$.

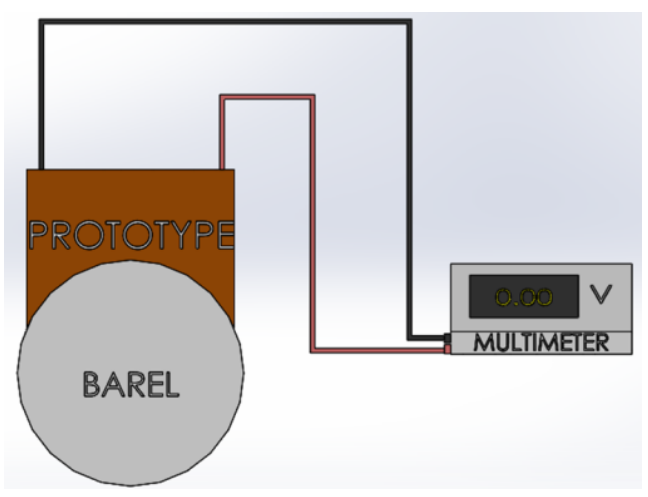

GAMBAR 4. Pengujian rangkaian terbuka

Pada pengujian alat dengan rangkaian terbuka, thermoelektrik akan langsung disambungkan ke modul termoelektrik yang nantinya akan menampilkan nilai dari tegangan dan arus yang dihasilkan oleh termoelektrik. Pada rangkaian diatas, terlihat bahwa tidak ada beban atau hambatan yang dipasang pada rangkaian, dengan kata lain bahwa nilai tegangan dan arus yang muncul pada moduk termoelektrik belum tereduksi oleh hambatan.

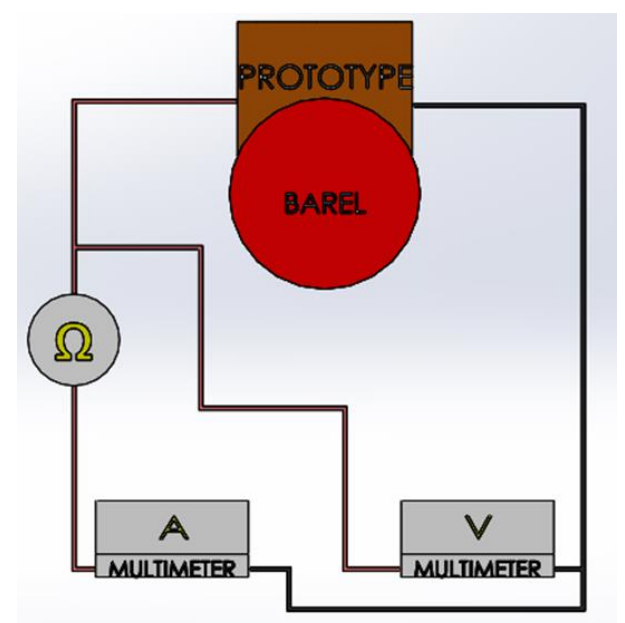

GAMBAR 5. Pengujian rangkaian terbuka

Pada pengujian dengan menggunakan rangkaian tertutup, termoelektrik akan diberi beban atau hambatan berupa lampu LED dan port USB lalu baru akan terhubung ke modul termoelektrik. Maka dapat disebut bahwa nantinya akan ada 2 output hasil dari termoelektrik, yaitu lampu LED dan juga port USB yang nantinya akan dihubungkan dengan kipas pendingin pada heat 
sink. Dan nilai yang akan muncul pada modul termoelektrik adalah nilai yang sudah tereduksi oleh output yang dipasang pada rangkaian. Urutan dari metodelogi penelitian ini dapat dilihat pada Gambar 6 .

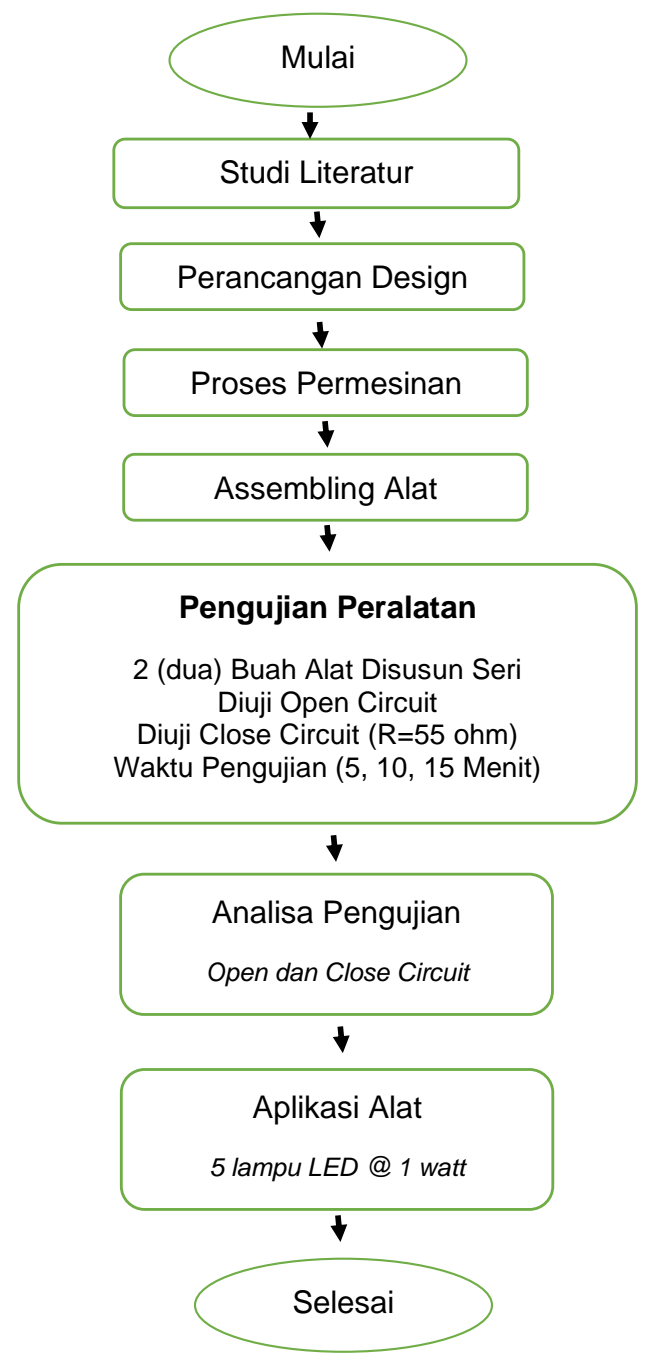

GAMBAR 6. Flow chart penelitian

\section{HASIL DAN PEMBAHASAN}

\section{Pembuatan Alat}

Setelah perancangan alat selesai, proses selanjutnya pembuatan part - part alat. Hasil pengerjaan part-part $\neg$ prototype, part dirakit dan dirangkai dan melewati beberapa proses penyempurnaan bentuk agar proses penyaluran panas dari barel menuju termoelektrik efektif. Hasil jadi prototype beserta perangkatperangkat pengukurnya dapat dilihat pada Gambar 7.
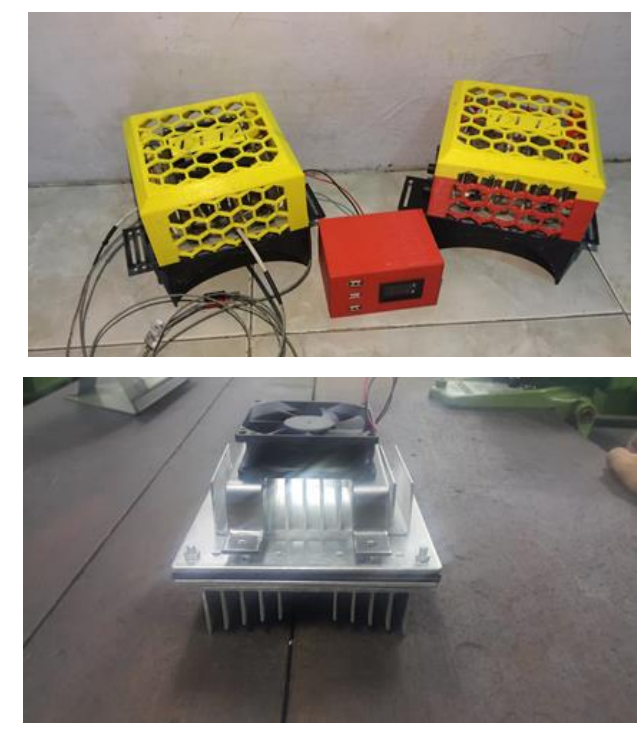

GAMBAR 7. Hasil pembuatan alat dengan dan tanpa cover.

\section{Pengujian Alat}

Penempatan alat diatas barel mesin injeksi dapat dilihat pada gambar 8 .

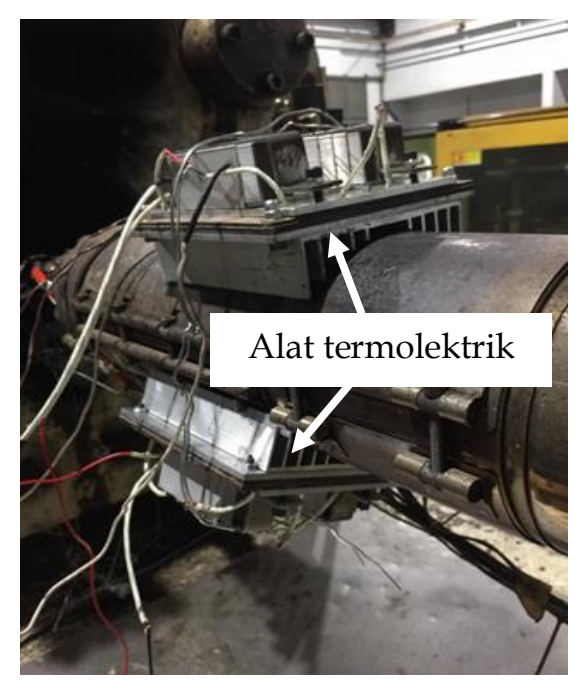

GAMBAR 8. Posisi alat saat pengujian

Agar prototipe dapat dengan efektif menyerap panas buangan dari mesin injeksi, maka pada bagian bawah prototipe akan dibuat permukaan yang serupa dengan permukaan barel, yang artinya permukaan penghantar panas konduksi yang menempel pada barel akan sebesar sisi alas termoelektrik sehingga panasnya pun akan merambat secara maksima.

Pengukuran dilakukan pada pengukuran suhu, tegangan dan arus dengan menggunakan 
multimeter. Pemasangan alat uji dan proses pengambilan data ditunjukkan pada Gambar 9.

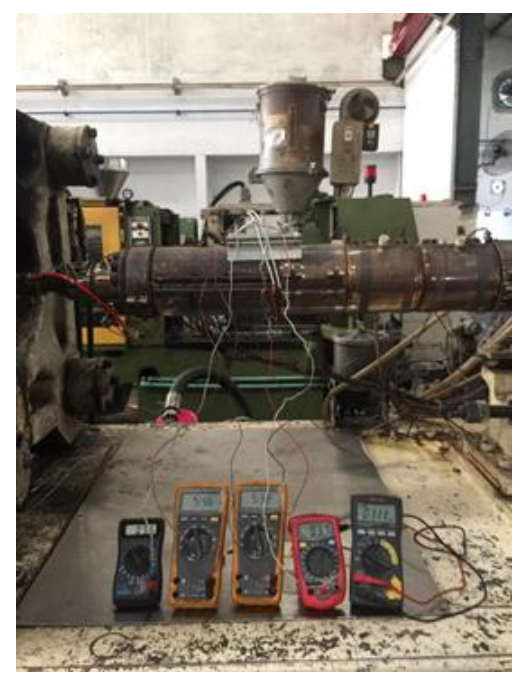

GAMBAR 9. Pengambilan data alat termoelektrik

Pengujian dilakukan dengan output listrik tanpa menggunakan modul step up untuk meningkatkan daya yang diharapkan. Hasil pengujian rangkaian terbuka dapat dilihat pada Tabel 1 .

TABEL 1. Hasil pengujian rangkaian terbuka 2 alat dengan modul step-up

\begin{tabular}{|c|c|c|c|c|c|}
\hline \multicolumn{6}{|c|}{ Pengujian Terbuka } \\
\hline \multicolumn{2}{|c|}{ Set Point Mesin } & $=$ & \multicolumn{3}{|l|}{$240^{\circ} \mathrm{C}$} \\
\hline \multicolumn{2}{|l|}{ No Barel } & $=$ & \multicolumn{3}{|l|}{3} \\
\hline Waktu & $\mathrm{THs} \downarrow$ & TPlate $\downarrow$ & TPlate $\uparrow$ & $\mathrm{THs} \uparrow$ & $\operatorname{Teg}(V)$ \\
\hline 5 & 78 & 72 & 51 & 44 & 10,44 \\
\hline 10 & 96 & 87 & 64 & 54 & 10,72 \\
\hline 15 & 108 & 97 & 75 & 64 & 10,80 \\
\hline
\end{tabular}

Tabel 1 menunjukkan hasil tegangan terbesar yang dihasilkan dengan penggunaan modul step-up yaitu sebesar $10,80 \mathrm{~V}$ dengan temperatur sisi panas sebesar $97^{\circ} \mathrm{C}$ dan temperatur sisi dingin sebesar $75^{\circ} \mathrm{C}$ yang terukur pada menit ke-15. Hasil pengujian rangkaian tertutup dapat dilihat pada Tabel 2.

TABEL 2. Hasil pengujian rangkaian tertutup

2 alat dengan modul step-up

\begin{tabular}{|c|c|c|c|c|c|c|}
\hline \multicolumn{7}{|c|}{ Pengujian 2 Prototype Tertutup Dengan Step Up } \\
\hline \multicolumn{2}{|c|}{ Set Point Mesin } & $=$ & \multicolumn{4}{|l|}{$220^{\circ} \mathrm{C}$} \\
\hline \multicolumn{2}{|c|}{ No Barel } & $=$ & \multicolumn{4}{|l|}{3} \\
\hline \multicolumn{2}{|l|}{ Beban } & $=$ & \multicolumn{4}{|l|}{$15 \Omega$} \\
\hline Waktu & $\mathrm{THs} \downarrow$ & TPlate $\downarrow$ & TPlate $\uparrow$ & THs $\uparrow$ & $\operatorname{Teg}(\mathrm{V})$ & $\operatorname{Arus}(\mathrm{A})$ \\
\hline 5 & 82 & 74 & 51 & 42 & 2,6 & 0,12 \\
\hline 10 & 97 & 88 & 63 & 54 & 2,64 & 0,12 \\
\hline 15 & 108 & 97 & 73 & 62 & 2,64 & 0,13 \\
\hline
\end{tabular}

Tabel 2 menunjukkan hasil tegangan dan terbesar yang dihasilkan dengan penggunaan modul step-up yaitu sebesar 2,64 $\mathrm{V}$ dan arus sebesar 0,13 A dengan temperatur sisi panas sebesar $97^{\circ} \mathrm{C}$ dan temperature sisi dingin sebesar $73^{\circ} \mathrm{C}$ yang terukur pada menit ke- 15 .

\section{Pembahasan}

Pada rangkaian terbuka, semakin lama alat berada diatas barel, maka semakin besar pula perbedaan temperatur yang dialami alat. Hal ini disebabkan karena semakin banyak panas yang tersalur dari barel dan suhu ruangan yang semakin panas pula akan mempengaruhi suku dari prototype. Pada pengujian rangkaian tertutup yang diberi beban berupa lampu LED 1 watt $\sim 55 \Omega$ bahwa semakin lama alat berada diatas barel, maka semakin besar pula perbedaan temperatur yang dialami alat. Tegangan yang terjadi pada rangkaian terbuka lebih besar dari rangkaian tertutup karena pada rangkaian terbuka tegangan yang dihasilkan semuanya terukur oleh multimeter sedangkan pada rangkaian tertutup tegangan yang terbaca lebih kecil karena adanya beban dan dirangkai secara seri sehingga tegangan terbagi kepada beban yang diberikan.

\section{Aplikasi Alat}

Gambar 10 menunjukkan 2 buah alat yang disusun secara seri dapat diaplikasikan untuk menghidupkan 5 buah lampu LED mata 1 watt yang disusun secara parallel . Nantinya lampu tersebut akan digunakan untuk mendukung kegiatan produksi di bengkel sehingga dapat menghemat penggunaan listrik.

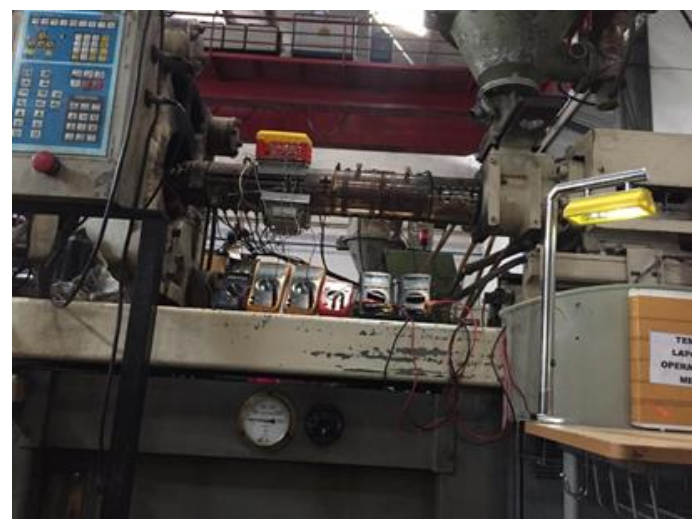

GAMBAR 10. Aplikasi alat pada bohlam lampu LED 


\section{KESIMPULAN}

1. Alat yang dihasilkan adalah sudah sesuai dengan desain. Dimensi sudah sesuai dengan perancangan desain yang dibuat (dari segi dimensi, dan berat prototype)

2. Pada rangkaian terbuka, hasil terbesar diperolah dari perbedaan suhu terbesar yang diterima oleh prototype. Semakin besar perbedaan temperatur, semakin besar pula tegangan yang dihasilkan.

3. Pada rangkaian tertutup, penggunaan/ pemasangan beban akan berpengaruh pada hasil yang dapat diukur oleh multimeter.

4. Pada pengaplikasian prototype, 5 buah lampu LED yang dirangkai secara parallel dan disambungkan dengan prototype dapat hidup dan lampu dapat digunakan untuk fasilitas pendukung proses produksi di bengkel.

\section{DAFTAR PUSTAKA}

Andrapica, G., Mainil, R. I., \& Aziz, A. 2015. Pengujian Thermoelectric Generator Sebagai Pembangkit Listrik Dengan Sisi Dingin Menggunakan Air Bertemperatur $10^{\circ} \mathrm{C}$. Jurnal Sains dan Teknologi, 14(2).

Anugrah, R.A., 2019. Studi Eksperimental Pengaruh Perbedaan Sudut Kemiringan terhadap Temperatur Onset Termoakustik Generator Gelombang Berdiri. Quantum Teknika: Jurnal Teknik Mesin Terapan, 1(1), pp.1-9.

Burlian, F., \& Khoirullah, M. I. 2014. Pengaruh variasi ketebalan isolator terhadap laju kalor dan penurunan temperatur pada Permukaan Dinding Tungku Biomassa. Jurusan Teknik Mesin, Universitas Sriwijaya.

Khalid, M., Syukri, M., \& Gapy, M. 2016. Pemanfaatan energi panas sebagai pembangkit listrik alternatif berskala kecil dengan menggunakan termoelektrik. Jurnal Karya Ilmiah Teknik Elektro, 1(3).

Ryanuargo, S. A., \& Sari, S. P. 2013. Thermoelectric Generator Mini Principles of Hot Steam Condensers in Refrigeration Systems. Journal of Rekayasa Elektrika, 10(4), 180-185.

\author{
Generator termoelektrik. Diakses dari \\ https://id.wikipedia.org/wiki/Generator_t \\ ermoelektrik, 21 januari 2019.
}

